\title{
ANTIOXIDANT POTENTIALS OF POLYPHENOLIC EXTRACTS FROM LEAVES OF TREES AND FRUIT BUSHES
}

\author{
SYLWIA CYBORAN ${ }^{1}$, DOROTA BONARSKA-KUJAWA ${ }^{1}$, IRENEUSZ KAPUSTA ${ }^{2}$, \\ JAN OSZMIAŃSKI ${ }^{3}$, HALINA KLESZCZYŃSKA ${ }^{1}$

\begin{abstract}
${ }^{1}$ Department of Physics and Biophysics, Wroclaw University of Environmental and Life Sciences, Norwida 25, 50-375 Wroclaw, Poland ${ }^{2}$ Faculty of Biology and Agriculture, University of Rzeszów, Ćwiklińskiej 2, 35-601 Rzeszów, Poland
\end{abstract} \\ ${ }^{3}$ Department of Fruit, Vegetable and Grain Technology, Wroclaw University of Environmental and Life Sciences, Norwida 25, Wroclaw, Poland
}

Received March 24, 2011; accepted May 24, 2011; published online June 01, 2011

\begin{abstract}
The aim of the work was to determine the antioxidant potential of extracts from leaves of strawberry, blackcurrant and apple in relation to lipids contained in the erythrocyte membrane. The studies performed have shown that the substances used protect membrane lipids against oxidation, clearly reducing the level of free radicals in erythrocyte ghosts suspension. The antioxidant activity of the substances studied follows the sequence: strawberry leaves $>$ apple leaves $>$ blackcurrant leaves. The results of the research on the antioxidant activity when confronted with the contents of polyphenols in the extracts indicates that the antioxidant potentials of the extracts depend both on the quantity and kind of individual polyphenols; in particular, on the kind and quantity of quercetin derivatives that constitute over $60 \%$ of all the phenolic compounds. Moreover, the high antioxidant activity of the extracts may be also due to other, nonphenolic substances that occur in leaves. The extracts exhibit very good properties as free radical scavenges, and can thus be used as cheap, easily available, natural antioxidants in the industries where natural antioxidants in the form of fruit extracts have been used for long.
\end{abstract}

\section{INTRODUCTION}

For many years now, all over the world have been conducted intensive studies of compounds that would protect biological systems against oxidation via regulation of free radical levels, without side effects. The human organism is incessantly exposed to the action of free radicals, which contribute to the aging of cells and cause many pathological conditions, e.g. arteriosclerosis, heart diseases and cancers (Beckman \& Ames, 1998; Middleton et al., 2000; Verlangieri et al., 1985). Such diseases arise in the course of physiological processes and as a result of internal and external physicochemical factors, e.g. ionizing radiation or xenobiotics (Bartosz, 2003). Therefore, in everyday diet and body care it is of vital importance to supply the organism with substances that reduce the levels of free radicals, especially when the natural protective systems do not perform well. To the natural compounds that provide protection against free radicals belong polyphenols. Their content in plant products depends both on the plant's fragment used for obtaining a polyphenol and many other factors, e.g. climatic conditions, maturity, time of harvest and storage conditions (Kalt et al., 1998; Crippen \& Morisson, 1986; Wang \& Lin, 2000). In the daily diet, the source of the precious for the organism compounds are mainly fruits, vegetables, herbs, cereals, spice plants and also juices, green tea and wine (Velioglu et al., 1998; Atoui et al., 2005; Gil et al., 2000). The compounds differ with respect to their availability for the human organism; their biological availability depending on several factors, among others on absorption, metabolism and excretion, both on the cellular and whole-organism levels (Manach et al., 2004). Such compounds can also be delivered to the organism in the form of plant extracts as medicines, dietary supplements and cosmetics. However, due to the phenolic compounds differentiation with respect to structure, polarity and stability in the reaction medium, their antioxidant potential may vary, and it depends on the share of individual phenolic components in an extract, and on the way and conditions of the extraction process, as well as on the method of analysis (Rice-Evans et al., 1996, Semenistaya \& Larionov, 2008). Precise determination of the composition of phenolic compounds in plant extracts and their antioxidant activity with respect to biological membranes is necessary for their rational and safe application to protect an organism against oxidation.

In the literature there are many papers where the antioxidant potential of phenolic compounds in fruits and fruit preserves is assayed, using various methods, (Velioglu et al., 1998; Wang et al., 1996; Proteggente et al., 2002). However, there are no studies on the 
antioxidant activity of phenolic compounds obtained from leaves of trees and fruit bushes with respect to membrane lipids. In the work Wang and Hsin-Shan (2000) a high antioxidant potential was found for polyphenols contained in fruits and leaves of various cultivars of raspberries. One can thus expect that in leaves of trees and fruit bushes there are antioxidant substances that protect biological membranes equally well. It seems substantiated to conduct studies on the antioxidant properties of extracts from leaves, having in view their prospective use as e.g. tea components.

The aim of the present work was to determine the antioxidant activity of polyphenolic extracts from leaves of apple tree, strawberry and blackcurrant towards the lipids of the erythrocyte membrane treated as a model of the biological membrane, and to determine the effect of polyphenolic compounds on that activity.

\section{MATERIALS AND METHODS}

\section{Materials}

Plant extracts were obtained from the Department of Fruit, Vegetable and Grain Technology, Wroclaw University of Environmental and Life Sciences. The percent content of polyphenols in the extracts was determined with the liquid chromatography (HPLC) method described by Oszmiański et al. (2008), phenolic compounds were identified with the HPLC-DAD method described in Oszmiański et al. (2009) and the method of UPLC-ESI-MS analysis.

UPLC conditions: LC System Equity UPLC Waters, column: BEH C18 2.1 x 50mm, $1.7 \mu \mathrm{m}$, temperature 50 ${ }^{\circ} \mathrm{C}$, flow rate $0.35 \mathrm{ml} / \mathrm{min}$, mobile: phase A: $0.1 \%$ acetic acid in water, phase B: $0.1 \%$ acetic acid in $40 \%$ acetonitrile, gradient: initial $80 \% \mathrm{~A}, 80 \% \mathrm{~A}-50 \% \mathrm{~A}$ in 3 min.

MS condition: all mass spectra were acquired using a triple quadruple mass spectrometer (Aquity TQD, Waters) equipped with electro spray ionization source. Negative-ion mass spectra were acquired. Negative-ion ESI was performed using a capillary voltage of $3.0 \mathrm{kV}$, and cone voltage $50 \mathrm{~V}$. Nebulization was achieved using nitrogen gas at a flow of $800 \mathrm{~L} / \mathrm{hr}$.

Desolvatation was aided using a temperature of 350 ${ }^{\circ} \mathrm{C}$. Mass spectra were recorded over the range $80-$ $1100 \mathrm{~m} / \mathrm{z}$. Tandem mass spectra were obtained using manual MS/MS by isolating the base peak (parent ion) from direct infusion. Samples were dissolved in $\mathrm{MeOH}$ and infused in the ESI source by syringe pump at flow rate of $5 \mu \mathrm{l} / \mathrm{min}$. The mass spectroscopic data were acquired and processed using MassLynx 4.1 software.

Polyphenols were isolated from leaves by extraction with water containing $200 \mathrm{ppm}$ of $\mathrm{SO}_{2}$, the ratio of solvent to leaves being 3:1. The extract was absorbed on Purolite AP 400 (UK) for further purification.

Table 1. Content of polyphenolic compounds in extracts from leaves of strawberry, apple tree and blackcurrant.

\begin{tabular}{|c|c|c|c|}
\hline Phenolic compound [\%] & $\begin{array}{l}\text { Apple } \\
\text { leaves }{ }^{1}\end{array}$ & $\begin{array}{c}\text { Blackcurrant } \\
\text { leaves }{ }^{2}\end{array}$ & $\begin{array}{c}\text { Strawberry } \\
\text { leaves }\end{array}$ \\
\hline chlorogenic acid & 0.92 & 1.15 & 0 \\
\hline neochlorogenic acid & 0 & 0.1 & 0 \\
\hline cryptochlorogenic acid & 0 & 0.11 & 0 \\
\hline ellagic acid & 0 & 0 & 0.89 \\
\hline derivate of caffeic acid & 0.12 & 0 & 0 \\
\hline derivate of p-coumaric acid & 0.29 & 0 & 0 \\
\hline p-coumaroyl-glucoside & 0.16 & 0 & 0.45 \\
\hline quercetin-3-O-galactoside & 3.40 & 2.52 & 0 \\
\hline quercetin-3-O-glucoside & 1.40 & 0 & 0 \\
\hline quercetin-3-(6"-malonyl) glucoside & 0 & 1.91 & 0 \\
\hline quercetin-3-0-arabinoside & 1.39 & 0 & 0 \\
\hline quercetin-3-0-xyloside & 2.44 & 0 & 0 \\
\hline quercetin-3-0-rhamnoside & 8.54 & 0 & 0 \\
\hline quercetin-3-0-glucosyl-6"-acetate & 0 & 5.33 & 0 \\
\hline quercitin-3-0-rutinoside & 0 & 0.33 & 5.23 \\
\hline quercitin-3-0-gl.glucuronide & 0 & 0 & 0.27 \\
\hline quercetin-3-0-glucunoronide & 0 & 0 & 2.81 \\
\hline phloretin-2'-0-xyloglucoside & 5.38 & 0 & 0 \\
\hline phloridzin & 2.98 & 0 & 0 \\
\hline kaempferol-3-0-rutinoside & 0 & 0.23 & 0.99 \\
\hline kaempferol-3-0-galactoside & 0 & 0.41 & 0 \\
\hline kaempferol-3-0-glucosyl-6"-acetate & 0 & 0.96 & 0 \\
\hline kaempferol-3-0-glucuronide & 0 & 0 & 0.12 \\
\hline TOTAL & 27.02 & 13.25 & 10.76 \\
\hline
\end{tabular}


The polyphenols were then eluted out with $80 \%$ ethanol, concentrated and freeze-dried. By means of the above method the mixture of polyphenols was obtained (Gąsiorowski et al., 1997). The percent content of polyphenols in individual preparations was determined by means of liquid chromatography HPLC ${ }^{1}$ (Oszmiański \& Wojdyło, 2005, 2007; Skupień \& Oszmiański, 2004) and HPLC-DAD ${ }^{2}$ (Oszmiański et al., 2009). The percent content of polyphenolic compounds in the extracts is given in Tab. 1.

Erythrocyte ghosts from fresh pig blood were obtained using the method of Dodge'a et al. (1963). The fluorescence probe DPH-PA (3-(p-(6-phenyl)-1,3,5hexatrienyl) was purchased from Molecular Probes, Eugene, Oregon USA. The oxidation inductor AAPH (2,2'-diazobis(2-amidinopropan) dichlorhydrate) was purchased from Aldrich-Sigma (USA). Glucosidated and galactosidated quercetin was purchased from Extrasynthese ${ }^{\circledR}$ (France).

Table 2. Chemical structure of quercetin derivatives used in the investigation.

\begin{tabular}{c|c}
\hline Phenolic compound & Chemical structure \\
\hline quercetin-3-O-glucoside & \\
quercetin-3-O-galactoside &
\end{tabular}

\section{Fluorimetric method}

The DPH-PA (3-(p-(6- phenyl)-1.3.5-hexatrienyl) probe was used in the fluorimetric experiments. Erythrocyte ghosts, with and without (control) addition of the extracts, were suspended in a phosphate buffer of $\mathrm{pH}=7.4$ and UVC irradiated or treated with the chemical oxidation inductor 2.2'-diazobis (2amidinopropan) dichlorohydrogen (AAPH) for $30 \mathrm{~min}$. A Carry Eclipsce spectrofluorimeter (Varian) was used to measure free radicals concentrations in samples. Excitation and emission wavelengths were $\lambda_{\mathrm{ex}}=364 \mathrm{~nm}$ and $\lambda_{\mathrm{em}}=430 \mathrm{~nm}$. The measure of lipid oxidation was the relative change in fluorescence intensity $-F / F_{0}$ where $F_{0}$ is the starting fluorescence and $F$ the one measured during the oxidation procedure (Arora \&
Strasburg, 1997). Percentage of lipid oxidation inhibition was calculated from the following formula:

$$
\% \text { of oxidation inhibition }=\frac{\left(F_{x}-F_{u}\right)}{\left(F_{k}-F_{u}\right)} \cdot 100 \%
$$

where:

$\mathrm{F}_{\mathrm{X}}$ - relative fluorescence of an UVC irradiated sample, or oxidized by AAPH, for $30 \mathrm{~min}$ in the presence of an extracts and compounds.

$\mathrm{F}_{\mathrm{U}^{-}}$relative fluorescence of the control sample, oxidized by AAPH or UVC irradiation, without extracts or compounds, measured after $30 \mathrm{~min}$.

$\mathrm{F}_{\mathrm{K}}$ - relative fluorescence of the blank sample, not subjected to oxidation procedures, measured after 30 $\min$.

The results of the assay were expressed relative to Trolox ${ }^{\circledR}$, in terms of TEAC (Trolox Equivalent Antioxidant Capacity).

\section{Spectrophotometric method}

Erythrocyte membranes were suspended in TrisEDTA of $\mathrm{pH}$ 7.4. Concentration of membrane proteins in the suspension was $1 \mathrm{mg} / \mathrm{ml}$ and was assayed with a method described in Bradford (1976). Adequate volumes of the compounds studied were added to successive samples, to obtain a final concentration from 0.005 to $0.5 \mathrm{mg} / \mathrm{ml}$. The control sample contained erythrocyte ghosts only. The samples thus prepared were irradiated with UVC emitted from a bactericidal lamp of $3.5 \mathrm{~mW} / \mathrm{cm}^{2}$ intensity. The degree of lipid oxidation was assayed on the basis of malondialdehyde (MDA) concentration released during lipid peroxidation. Concentration of MDA in samples after different times of irradiation was determined spectrophotometrically at $\lambda=535 \mathrm{~nm}$ based on the color reaction between MDA and thiobarbituric acid (TBA). Percentage of oxidation after 60 min irradiation, in presence of the extracts, was calculated from the formula:

$$
\% \text { inhibicji }=\frac{A_{0}-A_{B}}{A_{0}} \cdot 100 \%
$$

where:

$\mathrm{A}_{0}$ - absorption of control sample.

$\mathrm{A}_{\mathrm{B}}$ - absorption of sample containing a compound studied.

Based on the results obtained from both the methods used, the $\mathrm{IC}_{50}$ concentrations were determined at which occurs $50 \%$ inhibition of membrane lipids peroxidation. The $\mathrm{IC}_{50}$ values serve for comparing the antioxidant activity of the respective compounds.

The results obtained were statistically interpreted using STATISTICA 9.0, on the basis of the ANOVA variance analysis. The Dunnett test was used for difference estimation at confidence level $\alpha=0,05$. 


\section{RESULTS AND DISCUSSION}

\section{Fluorimetric method}

Irradiation of erythrocyte ghosts results in creation of free radicals and oxidation of membrane lipids. The UVC or AAPH-inductor induced free radicals cause quenching of DPH-PA probe fluorescence. As a measure of the extent of lipid oxidation has been assumed the relative fluorescence $\left(\mathrm{F} / \mathrm{F}_{\mathrm{o}}\right)$, i.e. the ration of the fluorescence of a sample oxidized with UVC or AAPH to the fluorescence measured prior to oxidation. In this method, blank probe was assumed to be the value of relative fluorescence of a sample containing erythrocytes suspension and DPH-PA probe before oxidation, while control was suspension of the same composition but oxidized with UVC or AAPH. Based on the results obtained, the kinetics of oxidation of membrane lipids in the presence of the extracts at various concentrations were determined. Representative curves of the kinetics for the extract of strawberry leaves oxidized with UVC radiation are presented in Fig. 1.

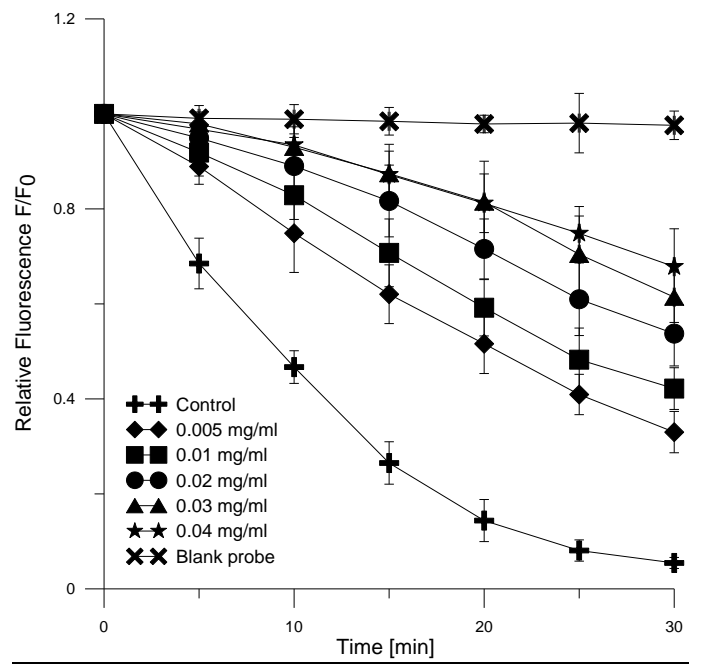

Fig. 1. Relative fluorescence vs. UVC irradiation time for suspension of erythrocyte ghosts: blank probe, control and with strawberry leaves extract at $0.005-0.04 \mathrm{mg} / \mathrm{ml}$ concentrations.

As seen from Fig. 1, relative fluorescence decreases with increasing time of irradiation. In the presence of the extract the decrease in fluorescence intensity is markedly smaller, and the curves are less steep. With the smallest concentration and after 30 min oxidation the number of free radicals in the solution decreased by $30 \%$, while with the highest by $80 \%$. Similar curves were obtained for the other extracts.

In this method, oxidation of erythrocyte membrane lipids was also induced with the chemical radical AAPH applied at $1 \mathrm{M}$ concentration. In the presence of all the compounds studied an increase in intensity of DPH-PA fluorescence occurred, caused by lower concentration of free radicals relative to control, but the kinetic curves for the compounds differed; this suggesting different molecular mechanisms of the interaction that caused the inhibition of lipid oxidation (Fig. 2).

Like in the case of membrane lipids irradiated with UVC, the relative fluorescence intensity decreases with time of their oxidation. That time is however different for different extracts, used at $0.005 \mathrm{mg} / \mathrm{ml}$. It can be seen clearly from Fig. 2 that strawberry leaves extract is the best free radical scavenger, whereas the other two extracts are good but weaker antioxidants, since the decrease in relative fluorescence for apple and blackcurrant leaves is substantially bigger, with respect to relative fluorescence for strawberry leaves extract.

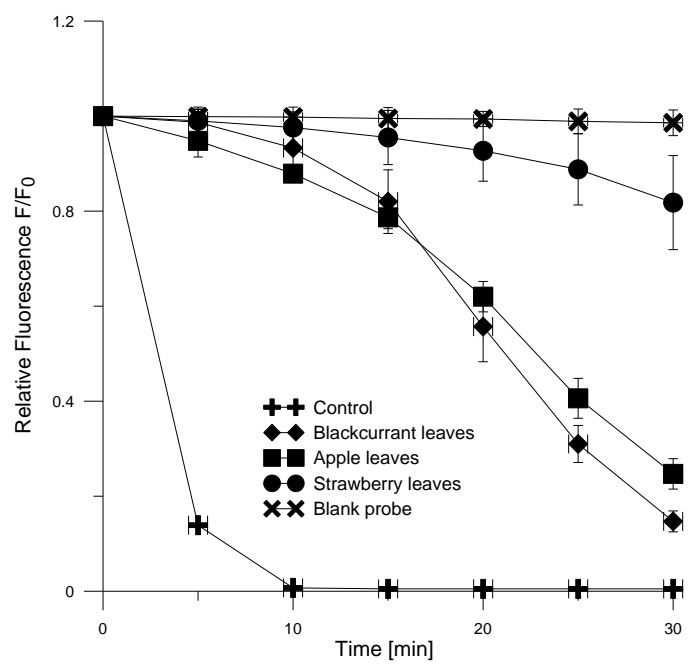

Fig. 2. Relative fluorescence as dependent on time of oxidation with AAPH; for blank, control and samples containing 0.005 $\mathrm{mg} / \mathrm{ml}$ extract of leaves of apple, strawberry and blackcurrant.

In order to compare the antioxidant activity of the substances used, on the basis of the relationships for 5 different concentrations and the selected $30 \mathrm{~min}$ time of irradiation the concentrations causing $50 \%$ inhibition of lipid oxidation $\left(\mathrm{IC}_{50}\right)$ were determined for the compounds and for Trolox ${ }^{\circledR}$ - the standard antioxidant substance. The $\mathrm{IC}_{50}$ values are given in Fig. 3.

The best protection against free radicals and oxidation was by strawberry leaves extract, this being confirmed both with membranes irradiated with UVC and treated with AAPH inductor. Moreover, in this method the strawberry extract exhibits activity comparable with that of Trolox ${ }^{\circledR}$. The apple and blackcurrant extracts exhibit similar activities but smaller than that of strawberry. When using different inductors of oxidation, the differences between $\mathrm{IC}_{50}$ values of the extracts are within measurement error. 


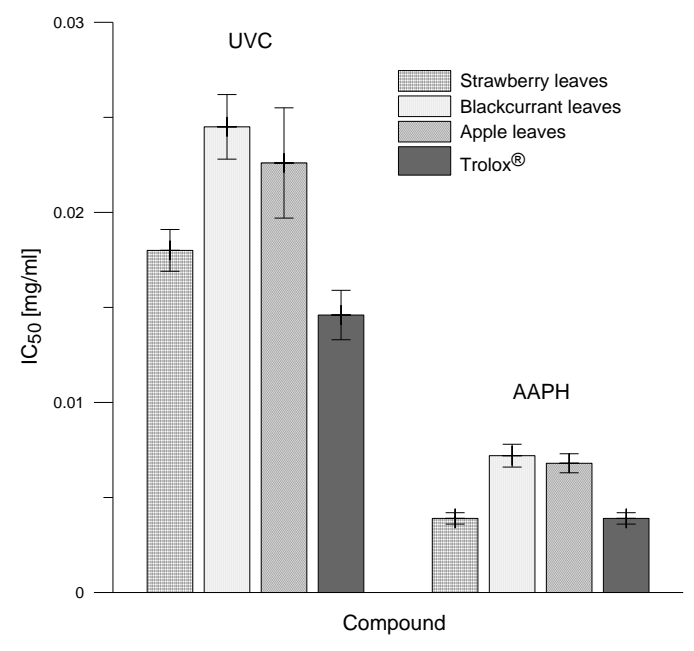

Fig. 3. $\mathrm{IC}_{50}$ values for extracts from leaves of strawberry, apple, blackcurrant and Trolox ${ }^{\circledR}$, found in the fluorimetric method. The oxidation was induced with UVC radiation or AAPH radical.

\section{Spectrophotometric method}

Like in the fluorimetric method, the results of measurements allowed us to draw kinetic curves of membrane lipids oxidation for 5 different concentrations in presence of the substances studied. As a measure of the extent of oxidation was assumed light absorption measured at $535 \mathrm{~nm}$ that increases with irradiation time. Fig. 4 shows representative curves for blackcurrant leaves extract applied at concentrations from 0.01 to $0.05 \mathrm{mg} / \mathrm{ml}$.

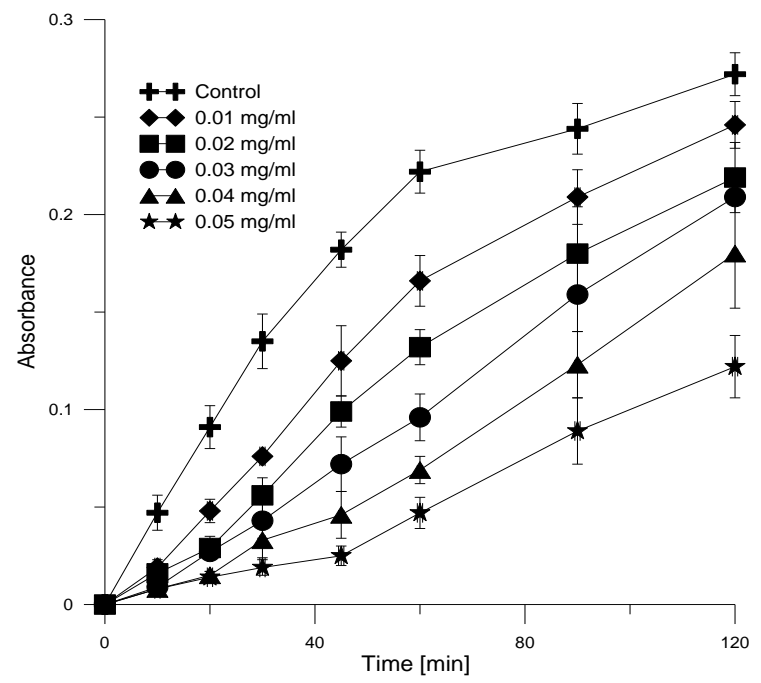

Fig. 4 Light absorption vs. time of UVC irradiation of erythrocyte ghosts; for control sample and with addition of blackcurrant extract at concentrations from 0.01 to 0.05 $\mathrm{mg} / \mathrm{ml}$.

The results presented in Fig. 4 indicate that light absorption in presence of blackcurrant leaves extract at various concentrations is lower compared with control, and its decrease depends on the extract concentration, indicating that the degree of membrane lipid oxidation is inhibited in presence of extract. The inhibition increases with increasing concentration of extract. Similar curves were obtained for the other extracts studied.

To compare the activities of the extracts, on the basis of the results obtained and for a selected 30 min time of irradiation, $\mathrm{IC}_{50}$ values were found for the extracts and for Trolox ${ }^{\circledR}($ Tab. 3).

Table 3. $\mathrm{IC}_{50}$ values for extracts and selected phenolic compounds contained in extracts and Trolox ${ }^{\circledR}$.

\begin{tabular}{lc}
\hline Compound & $\mathrm{IC}_{50}[\mathrm{mg} / \mathrm{ml}]$ \\
\hline Apple leaf & $0.0218 \pm 0.0026$ \\
Blackcurrant leaf & $0.0205 \pm 0.0012$ \\
Strawberry leaf & $0.0180 \pm 0.0015$ \\
Quercetin-3-O-galactoside & $0.0210 \pm 0.0012$ \\
Quercetin 3- O-glucoside $_{\text {Trolox }^{\circledR}}$ & $0.0158 \pm 0.0009$ \\
\hline
\end{tabular}

The results obtained in the spectrophotometric method allow to present the antioxidant activity of the extracts according to the following sequence: strawberry leaves $>$ blackcurrant leaves > apple tree leaves. All the extracts are good antioxidants, though with potency lower than Trolox ${ }^{\circledR}$.

Additionally, in order to determine the share of the polyphenols in the antioxidant activity of the extract, spectrophotometric studies were conducted of two chosen derivatives of quercetin: glucoside and galactoside. Quercetin derivatives are the dominant group of the polyphenols which occur in the extracts. Based on the results obtained, like for the extracts, kinetic curves were drawn for 5 concentrations of quercetin derivatives, and $\mathrm{IC}_{50}$ values were determined. They are given in Tab. 3 .

The antioxidant activity of the extracts is close to that of quercetin derivatives but lower than the activity of Trolox ${ }^{\circledR}$. The results obtained for quercetin derivatives indicate that the derivatives are weaker antioxidants than quercetin $($ TEAC $=0,446 \mathrm{mM}$ ) and their TEAC coefficients are: glucoside $0.948 \mathrm{mM}$, galactoside 1.26 $\mathrm{mM}$. Similar results were obtained by Rice-Evans et al. (1996), where the TEAC coefficient for quercetin-3-Orutinoside are 2 times lower than for quercetin, in free radical scavenging. Glucosidation of quercetin not only decreases its antioxidant activity but also increases its water solubility (Rice-Evans et al., 1997), thus decreasing its ability to permeate the lipid phase of membrane. It has been shown that the glucosides' ability to protect membranes against oxidation is diverse and can be connected with their weaker binding to biological membranes (Ferrali et al., 1997). Moreover, the lower antioxidant activity of quercetin derivatives is thought to be connected with the degree of glucosidation and structure of the sugar part, which causes blocking of the 
$3^{\text {rd }}$ hydroxyle group in the $\mathrm{C}$ ring of quercetin, preserving the 3',4'- dihydroxy structure in the $\mathrm{B}$ ring (Rice-Evans et al., (1997).

To determine the relation between the antioxidant activity of the substances studied and the content of phenolic compounds in an extract, the Pearson correlation coefficients were calculated, assuming that results with test probability $\mathrm{p}<0.1$ are statistically significant $(\mathrm{PU}=0.90)$. Concentration values $\mathrm{IC}_{50}$ were assumed as a measure of antioxidant activity.

The results obtained indicate at a lack of relationship between antioxidant activity of the extracts and total percent content of polyphenolic compounds $(r=0.847$, $\mathrm{p}=0.201)$. Moreover, a lack was also found of a statistically significant correlation between total percent content of quercetin glycosides and antioxidant activity of the extracts $(r=0,774, \mathrm{p}=0,296)$, even though the derivatives constitute over $60 \%$ of the phenolic compounds contained in the extracts.

\section{CONCLUSION}

The extracts investigated exhibit a high antioxidant activity, especially the strawberry leaf extract whose activity is close to that of Trolox ${ }^{\circledR}$, as documented by the fluorimetric studies. These substances, being effective antioxidants, insure a very good protection of erythrocytes against oxidation. In both the methods applied the most active is strawberry leaf extract, whereas apple tree and blackcurrant leaf extracts exhibit a good but lower activity. It is also shown that the activity of extracts containing a mixture of various polyphenols is close to the activity of the chosen quercetin derivatives (glucoside and galactoside), their activity being however lower than that of Trolox ${ }^{\circledR}$.

Based on the analysis of the extracts composition, we have found that apple extract is the richest in phenolic compounds, its phenolic compounds constituting $27 \%$ of all the components. Strawberry and blackcurrant extracts contain two times less phenolic compounds, approx. $10 \%$ and $13 \%$, respectively.

The results obtained indicate at a lack of linear relationship between the antioxidant activity of the extracts towards erythrocyte membrane and percent content of phenolic compounds. This means that phenolic compounds can interact with each other and with other phenolic constituents of the extracts, increasing or decreasing their antioxidant potential. That potential may depend on such factors as: reactivity of hydrogen or electron-donating agents, ability to stabilize and delocalize the unpaired electrons that arise in follow-up reactions, reactivity towards other antioxidants and the transition metal- chelating potential (Rice-Evans et al., 1996).
Quercetin derivatives belong to the main phenolic constituents of the extracts studied. The apple leaf extract contains $64 \%$ of the compounds and those of blackcurrant and strawberry over $77 \%$. Thus, it seems likely that the antioxidant activity of the extract is connected mainly with activity of quercetin glucosides, whose quantitative and qualitative composition in the substances used is differentiated.

The investigation performed indicate at a lack of correlation between the antioxidant activity of the extracts and the total content of quercetin derivates, which are known to have different antioxidant potential connected with their chemical structure and possibly different ability to bind to the erythrocyte membrane. So, it is likely that the antioxidant potential of the extracts depends not only on the overall phenolic composition, but also on the kind and amount of individual phenolic compounds, those of quercetin mainly. However, it should be kept in mind that aside of quercetin derivatives the extracts contain also trace amounts of other polyphenols that can variously affect their antioxidant activity. Since the extracts contain other compounds aside of phenolic ones, they are likely to affect their activity. Those are the antioxidant substances contained in leaves such as: alkaloids, carotenoids, tocoferols or ascorbic acid (Velioglu et al.,1998).

The extracts used in this investigation, as good, natural antioxidant, may successfully be applied in various branches of industry, e.g. the food industry as food additives, pharmaceutics industry as medicinal components and dietary supplements, and cosmetics industry as cream additives.

\section{ACKNOWLEDGMENTS}

This work was sponsored by Ministry of Science and Education, grant no. N N305 337034.

\section{REFERENCES}

Arora A. \& Strasburg G. M. (1997). Development and validation of fluorescence spectroscopic assays to calculate antioxidant efficacy. J. Am. Oil Chem. Soc., 74, 1031-1040.

Atoui A. K, Abdelhak M. \& Boskou G. (2005). Tea and herbal infusions: Their antioxidant activity and phenolic profile. Food Chem., 89(1), 27-36.

Bartosz G. (2003). Another face of oxygen, Warszawa PWN.

Beckman K. B. \& Ames B. N. (1998). The free radical theory of aging matures. Physiol. Rev., 78(2), 546-581.

Bradford M. M. (1976). Rapid and sensitive method for quantization of microgram quantities of protein utilizing the principle of protein-dye binding. Anal. Biochem., 72, 248254.

Crippen Jr. D. D. \& Morrison J. C. (1986). The effects of sun exposure on the phenolic content of cabernet sauvignon 
berries during development. Am. J. Enol. Vitic., 37(4), 243247.

Dodge J. T., Mitchell C. \& Hanahan D. J. (1963). The preparation and chemical characteristics of hemoglobin-free ghosts of erythrocytes. Arch. Biochem., 100, 119-130.

Droge W. (2002). Free radicals in the physiological control of cell function. Physiol. Rev., 82(1), 47-95.

Ferrali M., C. Signorini C., Caciotti B., Sugherini L., Ciccoli L., Giachetti D. \& Comporti M. (1997). Protection against oxidative damage of erythrocyte membrane by the flavonoid quercetin and its relation to iron chelating activity. FEBS Lett. 416, 123-129.

Gąsiorowski K., Szyba K., Brokos B., Kołaczyńska B., Jankowiak-Włodarczyk M. \& Oszmiański J. (1997). Antimutagenic activity of anthocyanins isolated from Aronia melanocarpa fruits. Cancer Lett., 119, 37-46.

Gil M. I., Tomas-Barberan F. A., Hess- Pierce B., Halcroft D. M. \& Kader A. A. (2000). Antioxidant activity of pomegrante juice and its relationship with phenolic composition and processing. J. Agric. Food Chem., 48(10), 4581-4589.

Kalt W., Forney C. F. \& McDonald J. (1998). Changes of fruit phenolic composition and antioxidant capacity during storage. Hort. Science, 33, 469 (abstract).

Manach C., Scalbert A., Morand C., Rémésy C. \& Jiménez L. (2004). Polyphenols: food sources and bioavailability. Am. J. Clin. Nutr., 79(5), 727-747.

Middleton E., Kandaswamy C. \& Theoharides T. C. (2000). The effect of plant flavonoids on mammalian cells, implications for inflammation, heart disease and cancer. Pharm. Rev., 52, 673-751.

Oszmiański J. \& Wojdyło A. (2005). Aronia melanocarpa phenolics and their antioxidant activity. Eur. Food Res. Technol., 221, 809-813.

Oszmiański J. \& Wojdyło A. (2007). Effects of various clarification treatments on phenolic compounds and color of apple juice. Eur. Food Res. Technol., 224, 755-762.

Oszmiański J., Wolniak M., Wojdyło A. \& Wawer I. (2008). Influence of apple puree preparation and storage on polyphenol contents and antioxidant activity. Food Chem., 107, 1473-1484.
Oszmiański J., Wojdyło A. \& Kolniak J. (2009). Effect of enzymatic mash treatment and storage on phenolic composition, antioxidant activity, and turbidity of cloudy apple juice. J. Agric. Food Chem., 57(15), 7078-7085.

Proteggente A. R., Pannala A. S., Paganga G., Van Buren L., Wagner E., Wiseman S., Van de Put F., Dacombe C. \& Rice-Evans C. A. (2002). The antioxidant activity of regularly consumed fruit and vegetables reflects their phenolic and vitamin C composition. Free Radical Res., 36(2), 217-233.

Rice- Evans C. A., Miller N. J. \& Paganga G. (1996). Structure - antioxidant activity relationships of flavonoids and phenolic acids. Free Radical Biol. Med., 20(7), 933-956.

Rice-Evans C. A., Miller N. J. \& Paganga G. (1997). Antioxidant properties of phenolic compounds. Trends Plant Sci. 2,152-159.

Semenistaya E. N \& Larionov O. G. (2008). Characterization of the composition and antioxidant activity of plant extracts by HPLC with UV and amperometric detection. Pharm. Chem. J., 42(9), 43-48.

Skupień K. \& Oszmiański J. (2004). Comparison of six cultivars of strawberries (fragaria $\mathrm{x}$ ananasa duch.) grown in northwest Poland. Eur. Food Res Technol., 219, 66-70.

Velioglu Y. S., Mazza G., Gao L. \& Oomah B. D. (1998). Antioxidant activity and total phenolics in selected fruits, vegetables and grain products. J Agric. Food Chem., 46, 4113-4117.

Verlangieri A. J., Kapeghian J. C., el-Dean S. \& Bush M. (1985). Fruit and vegetable consumption and cardiovascular mortality. Med. Hypoth., 16, 7-15.

Wang H., Cao G. \& Prior R. L. (1996). Total antioxidant capacity of fruits. J. Agric. Food Chem. 44(3), 701-705.

Wang S. Y. \& Lin H-S. (2000). Antioxidant activity in fruits and leaves of blackberry, raspberry and strawberry varies with cultivar and developmental stage. J. Agric. Food Chem., 48(2), 140-146.

Zielinska M., Gulden M., Seibert H. (2003). Effects of quercetin and quercetin-3-O-glycosides on oxidative damage in rat C6 glioma cells. Eur. J. Pharmacol. Environ. Toxicol. Pharmacol., 13(1), 47-53 